\title{
Does the Attitude of Adolescents on Anti-Cyberbullying Affect Their Behavior?
}

\author{
Dong Jenn Yang ${ }^{1,}$ a, Shuang $\mathrm{Lu}^{2, b,}{ }^{*}$, Shu Chun Chen ${ }^{3, c}$, and Han Sun ${ }^{4, d}$ \\ 1,3 I-SHOU University, Kaohsiung City \\ ${ }^{2}$ HUAQIAO University, Fujian Province \\ 4 JINAN University, Shandong Province \\ aalimama@isu.edu.tw, b844765301@qq.com, censhouw@yahoo.com.tw, d2092897890@qq.com \\ ${ }^{*}$ Corresponding author
}

Keywords: Community websites, cyber bullying, theory of planned behavior, focus group interview

\begin{abstract}
Facebook is the most commonly used social website for Taiwanese teenagers, who use it to seek recognition. However, recent studies have found that cyber bullying is widespread problem that imposes a negative impact on teenagers. This study used focus group, semi-structured interviews to explore and explain how attitudes, subjective norms and perceived behavioral control factors influence adolescents' intention to engage in anti- cyberbullying activities on social networking sites. The results showed that the attitude of adolescents on anti-cyberbullying could not affect their behavior and enhancing the Adolescents' perceived behavioral control on anti-cyberbullying would affect behavioral intentions.
\end{abstract}

\section{Introduction}

Community websites have penetrated into most peoples' daily life. Interpersonal interaction or expression of ideas in community websites have become a mainstream activity for teenagers. According to (survey), in (year) $88 \%$ of Taiwanese were Facebook users; about $40.4 \%$ of individuals aged 12 to 20 used the Internet to engage in social networking sites such as Facebook ${ }^{[1,2]}$. Teenagers are among those who can be easily involved in online bullying. According to the data of "Youth Risk Behavior Monitoring System" in 2017, 14.9\% of high school American students have been bullied in the Internet. Moreover, a survey in Britain had shown that $47 \%$ of young people indicated that they had received malicious comments online, and $62 \%$ admitted that they had published malicious comments through mobile applications ${ }^{[3]}$. These shows that cyberbullying has become a worldwide problem for teenagers.

This is a qualitative research which utilized a focus group interview method to understand how attitudinal factors, normative factors and perceived behavioral control factors affect cyberbullying. It is believed that when adolescents use social networking sites to seek for approval or recognition, behavioral attitudes, subjective normative factors (parents, teachers, peers, and reference groups), and perceived behavioral control factors could significantly affect their anti-cyberbullying behavior on social networking websites.

\section{Literature references}

The Theory of Planned Behavior (TPB) by Ajzen (1991) [4] holds that behavioral intentions are influenced by behavioral factors, subjective normative factors, and perceived control factors. Behavioral intent reflects an individual's willingness to adopt a particular behavior. Subjective norms are social pressures that individuals feel from individuals important to them when they take certain actions. Important others include family members, teachers, peers, and reference groups. Perceptual control refers to the process in which individuals perceive control when they expect to take a particular action, including internal and external control factors. The more resources and opportunities individuals think they have and the lesser the obstacles they anticipate, the stronger their control over perceptual behavior will be. 
Men and women seem to have equal chances of being the subject of cyberbullying. According to Olweus and Limber [5], adolescents aged 15 to 16 were the most tolerant of cyberbullying. Behavioral attitudes include behavioral intention and outcome evaluation. Subjective normative factors include normative beliefs and compliance motivation. Liao et al. [6] found that $41 \%$ of victims of cyberbullying would fight back in the same way, $59 \%$ would ignore it, and $16.4 \%$ would ask for help (e.g. law, teachers). The coping strategies include blocking contact with the bully (59\%), ignoring (46\%), leaving records and evidence $(42.6 \%)$, demanding for the other party to stop (21.3\%), changing of mobile phone number $(21.3 \%)$ and changing e-mail (3.1\%).

Subjective normative factors include normative beliefs and compliance motivation. The majority of parents supervise young people's use of the Internet in a free and relaxed way. According to $\mathrm{Wu}$ [7], parents generally attach importance to children's information education, but only $25 \%$ of parents supervise their children's Internet use. Ybarra and Mitchell [8] found that about $30 \%$ of young people use the Internet for more than three hours a day, and more than $50 \%$ of them use it without their parents' supervision.

\section{Research Methods}

This study used focus group interview, wherein a group of homogeneous consumers or customers are selected in the form of a small symposium and a trained host talks to them in the natural form, so as to gain a deep understanding of the relevant issues [9]. Focus groups are based on interaction between participants, so it is very important to select suitable respondents; thus, it is preferable to select those with similar social background characteristics. For this study, second-year students of a higher vocational college in Kaohsiung who use community websites were chosen as interviewees. They were aged 16 and 17 years old, have homogeneous characteristics, and could easily be led to interaction, which is conducive in understanding and exploring phenomenon with specific problems or behaviors [10].

Interviews were arranged in a sitting-in manner so that each interviewee can clearly see and listen to other people's remarks to help them interact with each other during the discussion. The observer was tasked to record the interview and observe the interviewee's attitude towards the question carefully. Finally, content analysis was done and the results are shown in Table 1. The interview lasted for approximately 60 minutes and is located in the McDonald's forum. Each meta-interview object was coded as MA-MD for males and FA-FC for females.

Table 1. Questions for Focus Group Interview

\begin{tabular}{|c|c|}
\hline Research Objective & Interview Topics \\
\hline $\begin{array}{l}\text { Identification of participant traits } \\
\text { and open interviews }\end{array}$ & $\begin{array}{l}\text { Q1: What are the social networking sites you often use? } \\
\text { Q2: Are your parents or senior teachers added or will you add } \\
\text { them as friends in the main account of your most frequently } \\
\text { used social networking site? }\end{array}$ \\
\hline Behavior and attitude factors & $\begin{array}{l}\text { Q3: Have you ever been bullied or have you bullied another } \\
\text { person on social networking sites? How? } \\
\text { Q4: What do you think of cyberbullying? }\end{array}$ \\
\hline $\begin{array}{l}\text { Subjective normative factors: } \\
\text { Individual normative belief and } \\
\text { motivation for compliance }\end{array}$ & $\begin{array}{l}\text { Q5: What are your parents', teachers', and friends' opinion about } \\
\text { cyberbullying? } \\
\text { Q6: Whose advice would you follow when responding to } \\
\text { cyberbullying? } \\
\text { Q7: Do you know any serious consequences of cyberbullying? } \\
\text { Examples include severe punishment as stated in the } \\
\text { school's rules and regulations, and compensation for } \\
\text { damages incurred. }\end{array}$ \\
\hline $\begin{array}{l}\text { Perceived behavior control: } \\
\text { Measurement of individual's } \\
\text { beliefs in internal and external } \\
\text { control and the effect of } \\
\text { perception on adolescents' } \\
\text { attitudes }\end{array}$ & $\begin{array}{l}\text { Q8: Can you decide on the content of the message or how to use } \\
\text { it? } \\
\text { Q9: Can you refuse friends or evade friends who jointly } \\
\text { implement cyberbullying on social networking sites? } \\
\text { Q10: School regulations and laws can protect me from } \\
\text { cyberbullying. }\end{array}$ \\
\hline
\end{tabular}




\begin{tabular}{|lr|}
\hline & Q11: A teacher can help me deal with cyber bullying. \\
\hline Intention to exhibit cyberbullying & Q12: What will you do when you witness cyber bullying? \\
behavior on social networking & I will persuade the bully to stop. \\
sites: The subjective probability & I will block or delete the bully in my account. \\
that teenagers may engage in & I will pretend to be okay. \\
cyberbullying behavior & Cyberbullying is normal. When I see eye to eye with you, I \\
& will support the cyberbullying by commenting on the post. \\
\hline
\end{tabular}

\section{Analysis of Research Results}

\subsection{Current Status of Community Websites among the Youth}

The most commonly used social networking website for all interviewees in Q1 was Facebook. They also indicated that they are keen on using social networking sites. Six respondents in Q2 agreed that they will invite parents or senior teachers as friends on their main account on social networking sites. Only MD was unwilling to add parents or senior teachers as friends, and MA, MB, MC, FA and FC indicated that they would deliberately not let parents or senior teachers know about bad or malicious words spoken/written by them against their peers or discussions on the opposite sex in some situations. Based on these, the following are concluded:

1. Facebook is the most frequently used social website for teenagers, and it is used to seek for identity, approval, or recognition.

2. Teenagers are willing to let their parents or senior teachers know about their activities on social networking sites, but in very seldom cases (when speaking ill of their peers or discussing the opposite sex), they would deliberately hide information form them and would oppose parental intervention.

\subsection{Behavioral Attitudes}

Q3 was aimed to understand teenagers' attitudes towards the emotions, perceptions, and behaviors concerning cyberbullying on social networking sites. Meanwhile, Q4 was intended to explore how adolescents evaluate the results and consequences of cyberbullying on social networking sites. Only one participant admitted in Q3 that he had been bullied. Others said that they have witnessed their friends being bullied on social networking sites. All respondents in Q4 rated the results and consequences of cyberbullying on social networking sites as neutral. Although adolescents have a neutral attitude towards cyberbullying on social networking sites, they still think and reflect on it in many ways. According to the respondents, they evaluate first whether their response would further aggravate the cyberbullying and would lead to more serious consequences; therefore, this study concludes that adolescents have a weak positive attitude towards anti-cyberbullying.

\subsection{Subjective Norms}

Q5 was intended to explore the normative impact of parents', teachers', and peers' perception on adolescents' attitude towards cyberbullying. Q6 and Q7 were meant to explore whether adolescents follow the advice of their parents, teachers, peers, or reference groups. The results of Q5 showed that the perception of important individuals (parents, teachers, peers) exert a positive impact on adolescents' behavior towards cyberbullying behavior. In the event of cyberbullying, only MA responded that they will inform their parents voluntarily. Meanwhile, MC, MD and FC said that they will inform their friends voluntarily. Further, MD believes that informing his friends could curb cyberbullying. The results of Q6 and Q7 demonstrated that respondents would follow the advice of important others (parents, teachers, peers, reference groups, etc.). When parents, teachers and peers are informed of the incident of cyberbullying, MA, FA and FB said that they would mainly follow the advice of their parents; $\mathrm{MB}$ and $\mathrm{MC}$ would prioritize the advice of their teachers; and $\mathrm{MC}$ and MD would follow their friends. The study also found that $67 \%$ of female respondents would follow their parents' advice and 50\% of male respondents would follow their friends' advice. Only FB responded that their friends would be the last people they would ask for advice possibly because they had suffered or witnessed cyberbullying from them. All respondents were positive about the sanctions 
imposed by school regulations or laws on cyberbullies. In addition, FA expressed that although school regulations or laws may reduce cyberbullying, it is still not enough for bullies to refrain from doing the act; therefore, this study concludes that subjective normative factors have a positive effect on adolescents' attitude towards anti-cyberbullying.

\subsection{Perceptual Behavior Control}

Q8 explored how teenagers feel in controlling social network cyberbullying. Q9, Q10 and Q11 were intended to understand adolescents' positive, neutral, and negative attitudes towards the impact of external control factors when they are expected to adopt cyberbullying behavior on social networking sites. Among them, MB, MC, MD, FA and FB had neutral attitudes towards the contents of the community website; MA chose had a positive attitude; and FC had a negative attitude.

Based on the responses in Q9, Q10 and Q11, this study attempted to explore the influence of external perceptual behavior control on cyberbullying behavior of teenagers' in community websites. Among them, MA, FA and FB had positive attitudes on rejecting or avoiding friends who bully others in social networking sites. Consequently, $\mathrm{MB}, \mathrm{MC}, \mathrm{MD}$, and $\mathrm{FC}$ had negative attitudes on refusing or avoiding friends who bully others on social networking sites. In addition, MA, MD, and FB believe that school rules and laws could protect them from cyberbullying on the Internet. MB, MC, FA, and FC that school regulations and laws could protect them from cyberbullying on the Internet. The two participants responded to Q6 that they would deal with cyberbullying based on the recommendations of their teachers. MA, MC, MD, FA, and FB believe that teachers could help them deal with cyberbullying in social networking sites. However, they believe that neither parents, teachers, peers, or even school regulations or laws can effectively solve or curb cyberbullying. This study therefore, concludes that perceptual behavioral control has a weak negative influence on adolescents' attitude towards anti-cyberbullying.

\subsection{Cyberbullying Intentions in Community Websites}

Q12 explored the possible ways that adolescents deal with cyberbullying behavior on social networking sites in order to assess the subjective probability of cyberbullying behavior among adolescents. The purpose of this study was to analyze the probability of adolescents' cyberbullying through observation and judgment. This study concludes that adolescents' cyberbullying intentions on social websites are mainly negative and neutral based on the responses to Q12. None of the respondents expressed that they would persuade the perpetrators of cyberbullying. MD, FA and FB said that will just block or delete the bullies on their social media accounts. Meanwhile, MA, MB, $\mathrm{MC}$ and FC admitted that they will not block or delete the bullies on their accounts. Most respondents said that they would just pretend to be okay or unaffected when faced with cyberbullying. They also believe that cyberbullying is normal. According to MD and FA, when the opinions of cyberbullies agree with them, they believe that this is favorable towards them. On the other hand, MA, MB, MC, $\mathrm{FB}$, and $\mathrm{FC}$ believe that even if the opinions of cyberbullies agree with them, they will still think that the act is unfavorable. Therefore, this study concludes that:

1. adolescents have a neutral behavioral intention on anti-cyberbullying;

2. attitude and subjective norm does not have significant influence on adolescents' anticyberbullying intention; and

3. perceptual behavioral control and intention of adolescent on anti-cyberbullying have a same trend.

Table 2. Focus Interview Analysis

\begin{tabular}{ccccccccccccc}
\hline & Trait & \multicolumn{3}{c}{$\begin{array}{c}\text { Behavior } \\
\text { Attitude }\end{array}$} & \multicolumn{3}{c}{ Subjective Norm } & \multicolumn{2}{c}{ Perceptual Behavior Control } & $\begin{array}{c}\text { Behavioral } \\
\text { Intention }\end{array}$ \\
& Q1 & Q2 & Q3 & Q4 & Q5 & Q6 & Q7 & Q8 & Q9 & Q10 & Q11 & Q12 \\
MA & $\circ$ & $\triangle$ & + & $\triangle$ & + & + & + & + & + & $\triangle$ & - & $\triangle$ \\
MB & $\circ$ & $\triangle$ & + & $\triangle$ & + & + & + & $\triangle$ & - & - & $\triangle$ & $\triangle$
\end{tabular}




\begin{tabular}{|c|c|c|c|c|c|c|c|c|c|c|c|}
\hline $\mathrm{MC}$ & o & + & + & $\triangle$ & + & + & + & $\triangle$ & - & - & - \\
\hline MD & o & - & + & $\triangle$ & + & + & + & $\triangle$ & - & $\triangle$ & - \\
\hline FA & O & $\triangle$ & + & $\triangle$ & + & + & + & $\triangle$ & + & - & - \\
\hline FB & 0 & + & + & $\triangle$ & + & + & + & $\triangle$ & + & $\triangle$ & - \\
\hline $\mathrm{FC}$ & $\circ$ & $\triangle$ & + & $\triangle$ & + & + & + & - & - & - & $\Delta$ \\
\hline
\end{tabular}

Note: (+) means support for anti-cyberbullying; (-) means opposition to anti-cyberbullying; $(\triangle)$ means neutral attitude towards cyberbullying, $(\circ)$ means qualified participants.

\section{Summary and Suggestions}

Based on the results of this study, adolescents have a neutral behavioral intention towards cyberbullying. This study found that there was no obvious connection among the attitude, subjective norms, and anti-bullying intention. The combination of attitude and subjective norms had a positive influence on anti-bullying intention, but these were not enough for adolescents to have a positive antibullying behavioral intention. The perceived behavioral control on anti-cyberbullying and anticyberbullying behavioral intentions may have a positive correlation.

The reasons for this phenomenon may be due to the presence of power disequilibrium between the bully and the victims of the bully. Most teenagers are afraid that if they show anti-bullying behavioral intention, they may become targets of cyberbullying, so they choose to keep neutral. In addition, most bullying incidents that occurred in social networking sites have not yet been resolved, which makes people's perception on anti-bullying behavior less controllable. Regardless of external or internal forces, most adolescents have a neutral or even negative anti-bullying behavior intentions over time. Social marketing staff and future research could explore these two reasons.

\section{References}

[1] Academy of Political Science Graduate Examination, Today News, 2010.

[2] National Center for Education Statistics and Bureau of Justice Statistics. Retrieved from: https://www.stopbullying.gov/cyberbullying/what-is-it/index.html

[3] M. Sarah, Half of UK girls are bullied on social media, says survey, The Guardian, 2017.8.14.

[4] I. Ajzen, The Theory of Planned Behavior, Organizational Behavior and Human Decision Process, vol.50, p. 179-211, 1991.

[5] D. Olweus, S. P. Limber, Olweus bullying prevention program: Teacher guide. Hazelden, 2007.

[6] Kowalski, M. Robin, \& P. L. Susan, Electronic bullying among middle school students, Journal of adolescent health, vol.41(6), p. S22-S30, 2007.

[7] J. R. S. J. Riebel, R. S. Jäger, \& U. C. Fischer. Cyberbullying in Germany-an exploration of prevalence, overlapping with real life bullying and coping strategies, Psychology Science Quarterly, vol.51(3), p. 298-314, 2009.

[8] S. Shariff, T. Strong-Wilson, Bullying and new technologies: What can teachers do to foster socially responsible discourse in the physical and virtual school environments, Classroom teaching: An introduction, p. 219-240, 2005.

[9] $\mathrm{H} \mathrm{Hu}$, A study on the survey of cyber bullying among middle school students in China, Institute of National Education, 2010. 
[10]C. W. Bao, Exploratory study on the self-construction and presentation of women's beauty information programs to female listeners, a case study of "women's beauty information programs", Department of Information Communication, 2009. 